\title{
Guarda responsável de cães e gatos em Maringá - Paraná / Brasil
}

\author{
Responsible pet ownership of dogs and cats in Maringá - Paraná / Brazill \\ Guardián responsable de perros y gatos en Maringá - Paraná / Brasil
}

Recebido: 25/04/2021 | Revisado: 05/05/2021 | Aceito: 06/05/2021 | Publicado: 20/05/2021

\author{
Ana Eliza Garrut Kamal \\ ORCID: https://orcid.org/0000-0001-7543-9032 \\ Centro Universitário Ingá, Brasil \\ E-mail: ana.kamal@edu.unipar.br \\ Gabriela Maria Benedetti Vasques \\ ORCID: https://orcid.org/0000-0001-9062-2230 \\ Centro Universitário Ingá, Brasil \\ E-mail: prof.gabrielavasques@uninga.edu.br \\ Isaac Romani \\ ORCID: https://orcid.org/0000-0003-2128-8915 \\ Centro Universitário Ingá, Brasil \\ E-mail: prof.isaacromani@uninga.edu.br
}

\begin{abstract}
Resumo
Objetivou-se neste trabalho, identificar o perfil da guarda responsável de cães e gatos no município de Maringá-PR, assim como, avaliar e correlacionar com o perfil socioeconômico dos entrevistados. Para isso, 395 questionários foram aplicados, contendo seis questões sobre o perfil socioeconômico e 15 sobre o perfil de guarda responsável. Observou-se que 56,5\% dos entrevistados são mulheres. Independente do sexo, os entrevistados residem em sua maioria em casas, com idades entre 20 e 30 anos, graduação completa e renda familiar de dois a cinco salários mínimos. Quanto ao perfil de guarda responsável, $86,8 \%$ possuem animais de estimação, sendo que $75,8 \%$ dos entrevistados possuem cães, $14,3 \%$ cães e gatos e $7,9 \%$ apenas gatos. Observou-se 58,3\% dos entrevistados que não castraram seus animais e destes $43,9 \%$ possuem acesso livre à rua, contrapondo-se com entrevistados que castraram seus animais $(27,1 \%)$ e possui acesso a rua $(34,1 \%)$. O uso de ração como alimento para os animais é realizado pela maioria dos entrevistados e não se relaciona significativamente à renda familiar e escolaridade. Elevado percentual dos entrevistados declarou vacinar seus animais (75\%) e vermifugar (73,5\%). A renda familiar dos entrevistados é um fator importante com relação a periodicidade das consultas. Conclui-se que os diferentes aspectos da guarda responsável de animais de companhia na cidade de Maringá carece de atenção com relação aos programas de conscientização quanto ao controle populacional / acesso as ruas e programas de castração, que devem ser implementados ou aprimorados, assim como, novos estudos para o esclarecimento de demais aspectos da guarda responsável nesta região.
\end{abstract}

Palavras-chave: Animais de companhia; Bem-estar animal; Posse responsável.

\begin{abstract}
The main aim of this paper is to identify responsible custody's profile of cats and dogs in Maringá, Paraná. Brazil and measure its correlation with the socioeconomic profile of the interviewees. For that, 395 interviews were made, each containing six questions to measure socioeconomic profile and fifteen to measure the responsible custody profile. It was observed that $56.5 \%$ of the interviewees were female. Independing on gender, interviewees resided mostly on houses, aged from 20 to 30 years old, had completed superior education and had an income of two to five minimum wages. As to the responsible custody profile, $86.8 \%$ had pets, being $75.8 \%$ having only dogs, $14.3 \%$ having cats and dogs and $7.9 \%$ having only cats. It was observed that $58.3 \%$ had not neutered their pets and from those, $43.9 \%$ had free outdoors access, opposed to interviewees that had neutered their pets (27.1\%) and had free outdoors access (34.1\%). The use of dog food is administered from a majority of the interviewees and had no correlation to family income and education level. A high percentage of the interviewees stated to vaccine their pets $(75 \%)$ and gave vermicides (73.5\%). Interviewee income is an important factor in relation to doctor appointments frequency. It follows that the different aspects of responsible care in the city of Maringá lacks of attention from awareness campaigns for population control, free outdoors access and neutering programs, as new studies, to clarify other aspects of responsible custody in the region.
\end{abstract}

Keywords: Animal welfare; Responsible ownership; Pets.

\section{Resumen}

El objetivo de este trabajo és identificar el perfil de la guardian responsable de perros y gatos en la ciudad de Maringá - PR, así como, evaluar y correlacionar con el perfil socioeconómico de los entrevistados. Para ello, se aplicaron 395 
cuestionarios, que contenían seis preguntas sobre el perfil socioeconómico y quince sobre el perfil de custodia responsable. Se observó que el 56,5\% de los encuestados son mujeres. Independientemente del género, los encuestados residen principalmente en casas, con edades entre 20 y 30 años, graduación completa e ingresos familiares de dos a cinco salarios mínimos. En cuanto al perfil de custodia responsable, el 86,8\% tienen mascotas, siendo que $75,8 \%$ de los encuestados tienen perros, el 14,3\% perros y gatos y el 7,9\% solo gatos. Se observó que el $58,3 \%$ de los encuestados no castraron a sus animales y de estos el $43,9 \%$ tienen libre acceso a la calle, oponiéndose con los encuestados que castraron a sus animales $(27,1 \%)$ y tiene acceso a la calle $(34,1 \%)$. El uso de comida para animales como alimento es realizado por la mayoría de los encuestados y no está significativamente relacionado con los ingresos familiares y el nivel de escolarización. Un alto porcentaje de encuestados informó haber vacunado a sus animales $(75 \%)$ y desparasitar (73,5\%). Los ingresos familiares de los encuestados és un factor importante en relación con la frecuencia de las consultas. Se concluye que los diferentes aspectos de la custodia responsable de los animales de compañía en la ciudad de Maringá carece de atención relacionada a programas de sensibilización sobre control de población / acceso a calles y a los programas de castración, que deben implementarse o mejorarse, así como nuevos estudios para aclarar otros aspectos de la custodia responsable en esta región.

Palabras clave: Animales de companhia; Bienestar de los animales; Tenencia responsable.

\section{Introdução}

Acredita-se que a primeira espécie a ser domesticada pelo homem foi o cão há mais de 12.000 anos, entretanto, encontram-se relatos desta domesticação há mais de 100.000 anos (Young, 1985; Grandjean \& Vaissaire, 2001; Luescher, 2017). Já os felinos, mesmo possuindo artefatos egípcios há 2.600 a.c., não sustentam a hipótese de que naquela época estes animais já haviam sido domesticados (Young, 1985).

"O homem tem domínio sobre os animais, gostemos ou não", estas foram as primeiras palavras de Webster em seu livro: Animal Welfare: Limping Towards Eden (Webster, 2005), entretanto, esta convivência trouxe benefícios para os animais, com relação à disponibilidade de alimento e abrigo, e para os seres humanos que buscavam proteção (Heffner, 1999).

Segundo Heffner (1999) frente a esta convivência com benefícios mútuos, os animais domésticos se mantiveram mais resistentes à extinção, quando comparados aos ancestrais selvagens. Esta convivência é relatada há milênios e é utilizada nas mais variadas funções como animais de caça, de companhia, de guarda, transporte, detecção e busca de odores (Broom \& Fraser, 2010) e na função de cão guia (Young, 1985).

Após milhares de anos de domesticação dos animais, uma pesquisa nos Estados Unidos descreveu que os tutores de animais de estimação os tratam como membros da família, podendo possuir o sobrenome da mesma, além de referirem a si mesmos como pais de seu animal, dividirem a cama, passeios ao shopping, os presentear no Natal e mostrar que são considerados seus filhos, que recebem a mesma atenção que filhos humanos (Cohen, 2002; Oliveira, 2018).

Com a nova maneira de tratar os animais de companhia, o termo "posse responsável", apesar de ainda muito utilizado por parte da população, apresenta uma ideologia de que o animal se compara a um "objeto" que possui um "proprietário", o qual tem o direito sobre o animal, podendo usá-lo e abusá-lo de todas as formas possíveis, sendo assim, esta visão de "posse" e "coisificação da vida" já é considerada superada pelos direitos dos animais. Assim, o termo "posse" foi alterado para "guarda responsável", ao qual não apenas o termo foi alterado, mas também seu conceito, sendo mais abrangente e completo, promovendo a dignidade adequada ao animal (Santana \& Oliveira, 2006).

Diante disso, guarda responsável tem intuito de ensinar à sociedade que cuidar de um animal de companhia vai além de apenas proporcionar carinho, mas também obrigações que o guardião se compromete perante o animal, de acordo com suas necessidades físicas e mentais, ambientais, de saúde e também de prevenção da comunidade. Assim, deve haver planejamento na aquisição do animal, não se pode cometer abuso ou crueldade ao animal, abrigo limpo e arejado, com acesso à luz e que lhe permita movimentação, não abandonar o animal em via pública, não conduzir o animal em via pública de modo a expor perigo à comunidade, acesso a alimento e água fresca, realizar vacinas e vermifugações, realização de controle populacional e tratamento veterinário (Selby, Rhoades, Hewett, \& Irvin, 1979; Ciampo, Riccoa, Almeida, Bonilhac, \& Santos, 2000; 
Reichmann, Figueiredo, Pinto, \& Nunes, 2000; Dilly, Costa-Júnior, Freitas, \& Franceschini, 2005; Santana \& Oliveira, 2006; Canatto et al., 2012; Domingues, 2012; Loss et al., 2012; Catapan, Villanova-Junior, Weber, \& Rocha, 2015).

No ordenamento jurídico brasileiro os animais enquadram-se como produto, previsto no código civil (Lei nº 10.406 , 2002), entretanto, os maus-tratos são puníveis com reclusão, multa e proibição da guarda (Lei no 14.064, 2020). Na cidade de Maringá, vige uma lei que caracteriza e proíbe os maus-tratos aos animais, citando os como, por exemplo, não proporcionar tratamento médico adequado, promover distúrbio psicológico ao animal, eliminação de animais com objetivo populacional e não proporcionar eutanásia adequada (Lei n $\left.{ }^{\circ} 10.467,2017\right)$.

Por outro lado, parte da sociedade, desconhece ou ignora a dignidade animal, seja por falta de planejamento da guarda responsável, compra de animais por impulso, falta de interesse após empolgação inicial (Santana \& Oliveira, 2016), dependência emocional do animal, agressividade ocasionada pela própria relação entre animal e tutor (Figueiredo, 2001; Fortes et al., 2007) e a irresponsabilidade do tutor no momento que adquire ou adota um animal (Reichmann et al., 2000).

Para que medidas sejam tomadas a respeito do bem-estar dos animais de companhia, é necessário conhecer o perfil de seus tutores, a fim de identificar o público alvo, para que possam ser adotadas medidas estratégicas de divulgação da guarda responsável, informações estas, de grande relevância para os médicos veterinários e para o mercado pet. Diversos trabalhos e projetos sociais, relacionados à implantação de conceito de posse e guarda responsável, já foram realizados no Paraná, com a finalidade de conscientização da população quanto ao bem-estar animal e da comunidade. $\mathrm{O}$ trabalho mais próximo da cidade de Maringá-PR foi organizado pela UFPR na cidade de Palotina-PR, com o propósito de oferecer palestras à população sobre posse responsável. Em Curitiba-PR, Catapan et al., (2015) formulou um questionário para avaliar o perfil dos entrevistados e a respeito de seus animais de estimação, para confrontar informações de perfil socioeconômico com guarda responsável de animais.

Assim, a realização destes estudos em grandes centros urbanos é de grande importância. Até a presente data, nenhum trabalho foi realizado na cidade de Maringá / Paraná. Frente ao exposto, este trabalho teve por objetivo identificar o perfil da guarda responsável de cães e gatos neste município, assim como avaliar e correlacionar com o perfil socioeconômico dos entrevistados.

\section{Metodologia}

O presente estudo foi desenvolvido concomitantemente com a realização do Projeto de Extensão intitulado: "Conscientização Comunitária e Levantamento de Dados Sobre a Posse Responsável de Animais de Estimação" / 2017. Antes de sua execução, o mesmo foi submetido à apreciação pelo CEP/UNINGÁ, sendo aprovado no dia 02 de dezembro de 2016, sob registro no CAAE: 61223916.0.0000.5220.

Foi desenvolvido uma pesquisa de campo de caráter quantitativo-descritivo, transversal que caracteriza-se por apresentar precisão e controle estatístico, com intuito de fornecer dados para verificação de hipóteses (Marconi \& Lakatos, 2019). O estudo baseou-se na aplicação de um questionário para moradores na cidade de Maringá / PR, que se dispuseram a participar da pesquisa. Possuindo 21 questões com resposta de múltipla escolha, o formulário era composto de seis questões sobre o perfil socioeconômico do entrevistado e as demais voltadas à guarda responsável.

No perfil socioeconômico questionou-se: sexo, idade, tipo de residência (casa / apartamento), número de pessoas que moram na casa / apartamento, renda familiar e escolaridade. Nas questões sobre guarda responsável, questionou-se: se possui animais de estimação e motivo, no caso de não possuir, quais animais e quantidade, como foi adquirido, acomodação do animal, castração, se fica preso ou solto, alimentação, acesso à rua, como é conduzido em vias públicas, comportamento do animal, vacinação, vermifugação, conhecimento das vacinas, frequência ao pet shop e veterinário. 
Para o cálculo do número de questionários a serem aplicados considerou-se a população de Maringá de 397.473 mil habitantes (IBGE, 2017), nível de confiança de 95\%, erro amostral de 5\% e percentual mínimo de $60 \%$ de estimativa de residências que possuem cães e/ou gatos (Mori, 2020). Estes dados foram aplicados na equação 1 (Santos \& Castro, 2006):

$$
n=\frac{N \cdot Z^{2} \cdot p \cdot(1-p)}{Z^{2} \cdot p \cdot(1-p)+e^{2} \cdot(N-1)}
$$

Onde: $\mathrm{n}$ - número de questionários; $\mathrm{N}$ - população; $\mathrm{Z}$ - variável normal padronizada associada ao nível de confiança; $\mathrm{p}$ - verdadeira probabilidade do evento; e - erro amostral.

Trezentos e sessenta e nove questionários deveriam ser aplicados para que a pesquisa fosse significativa. Os mesmos foram aplicados nos meses de junho e julho de 2017, em diversas regiões do município de Maringá. Posteriormente, os dados foram tabulados utilizando-se o recurso do Formulários Google® para que os mesmos fossem extraídos em planilhas de Excel.

Inicialmente foram obtidas as frequências absolutas para cada evento de cada questionamento e, posteriormente, realizado o cálculo das frequências relativas. Buscou-se estabelecer correlações entre as diferentes questões, buscando associação entre o perfil socioeconômico e guarda responsável e entre as questões de guarda responsável. O teste de $X^{2}$ foi utilizado para avaliar diferenças estatísticas, com nível de significância de 5\% entre diferentes variáveis qualitativas, através do software Statistical Data Analysis R 4.0.3 / 2020, pacote R Commander (Fox, 2005).

\section{Resultados}

Foram aplicados 395 questionários, onde os entrevistados, além de participarem da pesquisa também foram orientados quando a guarda responsável de animais de companhia, sendo desta forma a pesquisa considerada significativa, visto que o número mínimo de questionários que deveriam ser aplicados era de 369, ou seja, 26 questionários a mais.

De todos os entrevistados, foi possível observar que a sua maioria era composta por mulheres $(56,5 \%)$, diferindo estatisticamente $(\mathrm{p}=0,0103)$ dos homens $(43,5 \%)$. Quanto à moradia, tanto homens quanto mulheres residiam em casas $(81,4 \%$ e $84,3 \%$, respectivamente).

Foi possível observar que, independentemente do sexo, houve prevalência entre entrevistados com idade entre 20 a 30 anos, sendo $37,7 \%$ mulheres e $57 \%$ homens (Figura 1), seguido por entrevistados de 10 a 20 anos, 33,6\% mulheres e 16,9\% homens.

Em relação ao grau de escolaridade, verificou-se que $87 \%$ dos entrevistados apresentam segundo grau e graduação completos, com $31,1 \%$ e $55,9 \%$, respectivamente. Demais graus de escolaridade foram observados em menor frequência, conforme o disposto na Tabela 1.

Dentre os entrevistados com primeiro grau completo, segundo grau completo e graduação completa, a renda predominante era de 2 a 5 salários mínimos (37\%, 46,3\% e 44,3\%, respectivamente), seguido por 1 a 2 salários mínimos para os que possuíam primeiro e segundo grau completos (25,9\% e $27,6 \%$ respectivamente), diferente dos entrevistados com graduação que, apresentavam entre 5 e 10 salários mínimos (24,9\%). Já entre os entrevistados com pós-graduação e doutorado completos, a maior frequência de renda salarial foi de 5 a 10 salários mínimos (42,9\% e 100\%), e com mestrado completo ficou igualmente entre 5 a 10 salários mínimos (50\%) e mais que 10 salários mínimos (50\%). 
Figura 1: Faixa etária dos entrevistados (n) do sexo masculino e feminino em relação à guarda responsável.

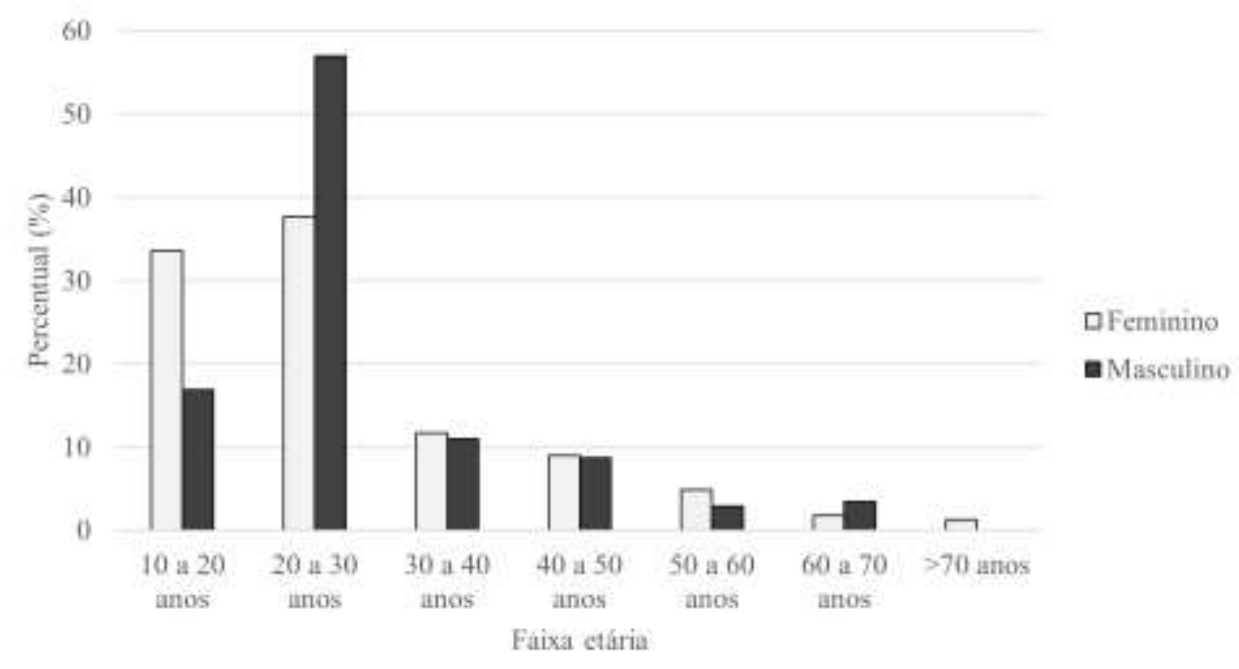

Fonte: Autores.

Tabela 1: Dados do grau de escolaridade e renda familiar dos entrevistados (n) sobre guarda responsável de cães e gatos de Maringá - PR.

\begin{tabular}{|c|c|c|c|c|c|c|c|}
\hline & Analfabeto & $1^{\circ} \mathrm{Grau}$ & $2^{\circ}$ Grau & G & PG & M & D \\
\hline Escolaridade & $5(1.3)$ & $27(6.8)$ & $123(31.1)$ & 221(55.9) & $14(3.5)$ & $4(1.0)$ & $1(0.3)$ \\
\hline Até 1 salário mín. & - & $3(11.1)$ & $2(1.6)$ & $3(1.4)$ & - & - & - \\
\hline De 1 a 2 salários mín. & $2(40.0)$ & $7(25.9)$ & $34(27.6)$ & $38(17.2)$ & $2(14.3)$ & - & - \\
\hline De 2 a 5 salários mín. & $2(40.0)$ & $10(37.0)$ & $57(46.3)$ & $98(44.3)$ & $3(21.4)$ & - & - \\
\hline De 5 a 10 salários mín. & $1(20.0)$ & $4(14.8)$ & $26(21.1)$ & $55(24.9)$ & $6(42.9)$ & $2(50.0)$ & $1(100)$ \\
\hline Mais que 10 salários mín. & - & $1(3.7)$ & $4(3.3)$ & $27(12.2$ & $3(21.4)$ & $2(50.0)$ & - \\
\hline Nenhuma renda & - & $2(7.4)$ & - & - & - & - & - \\
\hline
\end{tabular}

Notas: G - graduação; PG - pós-graduação; M - mestrado e D - doutorado. Fonte: Autores.

Foi possível observar que 86,8\% dos entrevistados possuem animais de estimação em sua residência (Tabela 2). Destes, $75,8 \%$ possuem apenas cães e 7,9\% apenas gatos, $14,3 \%$ possuem tanto cães quanto gatos e $2 \%$ possuem outros animais (aves, outros mamíferos e répteis). Apenas 13,2\% dos entrevistados não possuem nenhuma espécie de animal de estimação por diversos motivos, sendo que $30,8 \%$ consideram não possuir espaço para manter os animais, seguido por $28,8 \%$ que não possuem animais por falta de tempo para cuidar e, apenas 1,9\% devido às despesas geradas.

Observou-se que, independentemente do sexo, dentre os entrevistados que possuem apenas cães, o número médio por

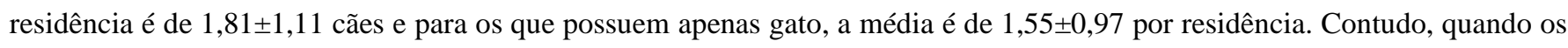

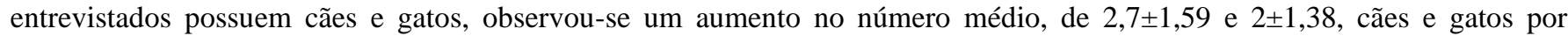
residência, respectivamente. Diferenças estatísticas significativas não foram observadas para o número de cães e gatos entre o sexo masculino e feminino. 
Tabela 2: Números / percentuais de entrevista que possuem ou não animais de companhia da cidade de Maringá - PR e motivos de não possuírem.

\begin{tabular}{lcc|lcc}
\hline \multicolumn{7}{c}{ Guarda de animais de companhia } \\
\hline & $\mathbf{n}$ & \multicolumn{2}{c}{$\%$} & n & $\%$ \\
\hline Sim & 343 & 86,8 & Não & 52 & 13,2 \\
\hline Apenas cães & 260 & 75,8 & Falta de tempo para cuidar & 15 & 28,8 \\
Apenas gatos & 27 & 7,9 & Não gosta de animais & 8 & 15,4 \\
Cães e gatos & 49 & 14,3 & Não tem espaço para manter & 16 & 30,8 \\
Apenas outros & 7 & 2,0 & Pelas despesas geradas & 1 & 1,9 \\
\end{tabular}

Fonte: Autores.

Dentre os entrevistados que possuem cães, foi possível observar (Tabela 3) que a maioria, independente do sexo, possuem apenas um cão em sua residência $(41,4 \%$ e $39,9 \%$, para entrevistados do sexo feminino e masculino, respectivamente), o mesmo foi observado para os gatos, $11 \%$ e $12 \%$, respectivamente.

Tabela 3: Dados de frequência de cães e gatos entre os entrevistados do sexo masculino e feminino sobre guarda responsável.

\begin{tabular}{|c|c|c|c|c|c|c|}
\hline & \multicolumn{3}{|c|}{ Feminino } & \multicolumn{3}{|c|}{ Masculino } \\
\hline & Cães & $\%$ & Todas as residências \% & Cães ou gatos & $\%$ & Todas as residências \% \\
\hline Animais & 227 & 59,0 & & 158 & 41,0 & \\
\hline 1 cão & 94 & 41,4 & 24,4 & 63 & 39,9 & 16,4 \\
\hline 2 cães & 32 & 14,1 & 8,3 & 39 & 24,7 & 10,1 \\
\hline 3 cães & 21 & 9,3 & 5,5 & 15 & 9,5 & 3,9 \\
\hline 4 cães & 16 & 7,0 & 4,2 & 8 & 5,1 & 2,1 \\
\hline$>5$ cães & 14 & 6,2 & 3,6 & 7 & 4,4 & 1,8 \\
\hline 1 gato & 25 & 11,0 & 6,5 & 19 & 12,0 & 4,9 \\
\hline 2 gatos & 14 & 6,2 & 3,6 & 3 & 1,9 & 0,8 \\
\hline 3 gatos & 4 & 1,8 & 1,0 & 2 & 1,3 & 0,5 \\
\hline 4 gatos & 1 & 0,4 & 0,3 & 1 & 0,6 & 0,3 \\
\hline$>5$ gatos & 6 & 2,6 & 1,6 & 1 & 0,6 & 0,3 \\
\hline
\end{tabular}

Fonte: Autores.

Contatou-se que $65,47 \%$ dos animais foram adquiridos através de adoções, seguido de $29,16 \%$ de compra e $5,37 \%$ dos entrevistados não souberam responder. Na casa dos entrevistados os animais possuem locais próprios, como casa, cama e canil, com 38,09\%, 37,2\% e 8,92\%, respectivamente. Estatisticamente a forma de aquisição (p=0,8 / p=0,5601) e acomodação ( $p=0,7824 / p=0,6759)$ não estão associados ao grau de escolaridade e renda familiar, respectivamente. 
Do total de entrevistados, 77,08\% declararam que os animais ficam soltos em suas residências, seguido de $15,47 \%$ que ficam soltos grande parte do dia e 6,25\% que ficam presos (1,2\% outras formas). Não houve diferenças estatísticas significativas com relação a forma com que os animais ficam nas residências com a escolaridade $(\mathrm{p}=0,9913)$ e renda familiar $(\mathrm{p}=0,4272)$.

Dos entrevistados que possuem cães, gatos ou ambos, 58,3\% não castraram nenhum de seus animais e destes, 43,9\% declararam que seus animais possuem acesso à rua. Já 27,1\% castraram todos seus animais e destes, 34,1\% possuem acesso livre (Tabela 4). Não se observou diferenças estatísticas significativas ( $\mathrm{p}=0,8457)$ entre possuir ou não animais castrados com acesso à via pública. Entre os animais que possuem acesso as vias públicas, 64,08\% são conduzidos com uso de coleiras e guias, seguido de $32,24 \%$ de possuem acesso livre (3,68\% outras formas).

Tabela 4: Dados referente ao número de entrevistados que castraram ou não seus animais em relação ao acesso à rua.

\begin{tabular}{lccc}
\hline Cães e gatos & Entrevistados & $\%$ & $\begin{array}{c}\text { Entrevistados que possuem } \\
\text { cães e gatos (\%) }\end{array}$ \\
\hline Não castrado & 196 & 58,3 & 25,6 \\
\hline Com acesso à rua & 86 & 43,9 & 32,7 \\
Sem acesso à rua & 110 & 56,1 & 2,7 \\
\hline Maioria não castrado & 20 & 6,0 & 3,3 \\
\hline Com acesso à rua & 9 & 45,0 & 2,4 \\
Sem acesso à rua & 11 & 55,0 & 6,3 \\
\hline Maioria castrado & 29 & 8,6 & \\
\hline Com acesso à rua & 8 & 27,6 & 9,2 \\
Sem acesso à rua & 21 & 72,4 & 17,9 \\
\hline Castrado & 91 & 27,1 & $\mathbf{1 0 0}$ \\
\hline Com acesso à rua & 31 & 34,1 & 65,9 \\
Sem acesso à rua & 60 & $\mathbf{1 0 0}$ & \\
\hline Total & $\mathbf{3 3 6}$ & & \\
\hline
\end{tabular}

Fonte: Autores.

Dentre os entrevistados que possuíam cães e gatos, a maioria declarou que seus animais não eram agressivos $(91,7 \%)$, sendo 55,8\% destes não castrados, seguido por 28,6\% castrados (Tabela 5). Apenas 3,3\% consideram seus animais como agressivos, sendo 90,9\% deles não castrados. Não foi observado relação entre o comportamento dos cães em relação a castração $(\mathrm{p}=0,1962)$.

Dos entrevistados que possuem cães, 73,5\% informaram que seus animais têm acesso livre às vias públicas, destes, 82,4\% que vivem em casa consideram seus cães dóceis, seguido por 14,4\% que vivem em apartamento e também os consideram dóceis (Tabela 6). Similarmente, os cães que não possuem acesso livre às vias públicas $(26,5 \%), 80,8 \%$ vivem em casa e são dóceis, seguido por $14,1 \%$ que também são dóceis e vivem em apartamentos. 
Tabela 5: Dados do comportamento de cães e gatos em relação à castração.

\begin{tabular}{ccc}
\hline Cães e gatos & Entrevistados & \% \\
\hline Animal agressivo & 11 & 3,3 \\
\hline Castrado & 1 & 9,1 \\
Não castrado & 10 & 90,9 \\
\hline Animal não agressivo & 308 & 91,7 \\
\hline Castrado & 88 & 28,6 \\
Maioria castrado & 29 & 9,4 \\
Maioria não castrado & 19 & 6,2 \\
Não castrado & 172 & 55,8 \\
\hline Outros & 17 & 5,1 \\
\hline Castrado & 3 & 17,6 \\
Maioria não castrado & 1 & 5,9 \\
Não castrado & 13 & 76,5 \\
\hline Total & $\mathbf{3 3 6}$ & $\mathbf{1 0 0}$ \\
\hline
\end{tabular}

Fonte: Autores.

Tabela 6: Dados de cães e gatos com acesso às vias públicas de acordo com sua residência e docilidade.

\begin{tabular}{lccc}
\hline Cães e gatos & Entrevistados & $\mathbf{\%}$ & $\begin{array}{c}\text { Entrevistados que possuem } \\
\text { cães ou cães e gatos\% }\end{array}$ \\
\hline Possui acesso a vias públicas & 216 & 73,5 & 10,5 \\
\hline Dócil / Vive em apartamento & 31 & 14,4 & 0,3 \\
Agressivo / Vive em apartamento & 1 & 0,5 & 60,5 \\
Dócil / Vive em casa & 178 & 82,4 & 2,0 \\
Agressivo / Vive em casa & 6 & 2,8 & 3,7 \\
\hline Não possui acesso a vias públicas & 78 & 26,5 & - \\
\hline Dócil / Vive em apartamento & 11 & 14,1 & 21,4 \\
Agressivo / Vive em apartamento & - & - & 1,4 \\
Dócil / Vive em casa & 63 & 80,8 & $\mathbf{1 0 0}$ \\
Agressivo / Vive em casa & 4 & 5,1 & $\mathbf{1 0 0}$ \\
\hline Total & $\mathbf{2 9 4}$ & & \\
\hline
\end{tabular}

Fonte: Autores.

Dos entrevistados que possuem cães ou gatos e oferecem apenas ração aos mesmos ( $\mathrm{p}=0,8167), 76,5 \%$ possuem renda familiar maior que 10 salários mínimos, seguido por 75,2\% que possuem renda de 2 a 5 salários mínimos, 71,4\% renda de até 1 salário mínimo, 70,5\% renda de 5 a 10 salários mínimos e, por fim, 65,7\% com renda de 1 a 2 salários mínimos (Tabela 7). Observa-se, desta forma, a preocupação dos entrevistados em fornecer alimento ideal aos seus animais, independente da renda familiar. 
Tabela 7: Confronto de dados a respeito de renda familiar e alimentação de cães e gatos.

\begin{tabular}{|c|c|c|c|}
\hline Renda & Entrevistados & $\%$ & $\begin{array}{c}\text { Entrevistados que possuem cães } \\
\text { e gatos } \%\end{array}$ \\
\hline Até 1 salário mín. & 7 & 2,1 & 2,1 \\
\hline Apenas ração & 5 & 71,4 & 1,5 \\
\hline Ração e comida caseira & 2 & 28,6 & 0,6 \\
\hline De 1 a 2 salários mín. & 67 & 19,9 & 19,9 \\
\hline Apenas ração & 44 & 65,7 & 13,1 \\
\hline Ração e comida caseira & 22 & 32,8 & 6,5 \\
\hline Apenas comida caseira & 1 & 1,5 & 0,3 \\
\hline De 2 a 5 salários mín. & 149 & 44,3 & 44,3 \\
\hline Apenas ração & 112 & 75,2 & 33,3 \\
\hline Ração e comida caseira & 37 & 24,8 & 11,0 \\
\hline De 5 a 10 salários mín. & 78 & 23,2 & 23,2 \\
\hline Apenas ração & 55 & 70,5 & 16,4 \\
\hline Ração e comida caseira & 21 & 26,9 & 6,3 \\
\hline Apenas comida caseira & 2 & 2,6 & 0,6 \\
\hline Mais que 10 salários mín. & 34 & 10,1 & 10,1 \\
\hline Apenas ração & 26 & 76,5 & 7,7 \\
\hline Ração e comida caseira & 8 & 23,5 & 2,4 \\
\hline Nenhuma renda & 1 & 0,3 & 0,3 \\
\hline Apenas ração & 1 & 100,0 & 0,3 \\
\hline Total & 336 & 100 & 100 \\
\hline
\end{tabular}

Fonte: Autores.

Conforme observa-se na Tabela 8, de acordo com a escolaridade dos entrevistados, apenas 0,5\% dos que possuem graduação completa e 1,9\% dos que possuem segundo grau completo, informaram alimentar seus cães e gatos exclusivamente com comida caseira. Os demais entrevistados, independentemente de sua escolaridade, possuem preferência por alimentar seus cães e gatos apenas com ração, percentuais entre 62,5\% (primeiro grau completo) e 75\% (analfabetos e mestrado completo).

Dentre os entrevistados que possuem cães e gatos, $75 \%$ declararam vacinar seus animais e destes, 56,7\% não realizaram a castração, seguido por 28,6\% que castram seus animais (Tabela 9). Os entrevistados que não vacinaram seus animais, correspondem a 17,9\%, destes, $61,7 \%$ não castraram e 21,7\% castraram. Dos entrevistados que não souberam responder se seus animais são vacinados (7,1\%), 66,7\% deles também não castram seus animais, seguido por $25 \%$ que castraram. Os percentuais observados, não diferiram estatisticamente quando se considera estado vacinal com a castração dos animais $(\mathrm{p}=0,8458)$, escolaridade $(\mathrm{p}=0,1871)$ e renda $(\mathrm{p}=0,5093)$. 
Tabela 8: Dados referentes ao grau de escolaridade e alimentação de cães e gatos.

\begin{tabular}{|c|c|c|}
\hline Escolaridade & Entrevistados & $\%$ \\
\hline Analfabeto & 4 & 1,2 \\
\hline Apenas ração & 3 & 75,0 \\
\hline Ração e comida caseira & 1 & 25,0 \\
\hline Primeiro grau completo & 24 & 7,1 \\
\hline Apenas ração & 15 & 62,5 \\
\hline Ração e comida caseira & 9 & 37,5 \\
\hline Segundo grau completo & 106 & 31,5 \\
\hline Apenas ração & 75 & 70,8 \\
\hline Ração e comida caseira & 29 & 27,4 \\
\hline Apenas comida caseira & 2 & 1,9 \\
\hline Graduação completa & 186 & 55,4 \\
\hline Apenas ração & 139 & 74,7 \\
\hline Ração e comida caseira & 46 & 24,7 \\
\hline Apenas comida caseira & 1 & 0,5 \\
\hline Pós-Graduação completa & 12 & 3,6 \\
\hline Apenas ração & 8 & 66,7 \\
\hline Ração e comida caseira & 4 & 33,3 \\
\hline Mestrado completo & 4 & 1,2 \\
\hline Apenas ração & 3 & 75,0 \\
\hline Ração e comida caseira & 1 & 25,0 \\
\hline Total & 336 & 100,0 \\
\hline
\end{tabular}

Fonte: Autores.

Entre os entrevistados que possuem cães e gatos, foi possível observar que, a renda é um fator importante com relação a periodicidade das consultas $(\mathrm{p}=0,0278)$ (Tabela 10). A grande maioria dos entrevistados levam seus animais ao veterinário apenas quando necessário. Observou-se que os entrevistados que não apresentam renda ou que recebem até 1 salário mínimo não levam seus animais ao veterinário ou quando necessário. Para as demais rendas (superiores) também se observou a declaração de não ida ao veterinário, porém em percentuais menores. Conforme observa-se a elevação da renda familiar, verifica-se aumento nas frequências de ida do animal ao veterinário, seja quinzenalmente, mensalmente, a cada três / seis meses

Entre os entrevistados que possuem cães, gatos ou cães e gatos, a grande maioria $(73,5 \%)$ realiza a vermifugação de seus animais e, mesmo havendo pouca diferença, quando o tutor possui mais de um animal há maior prevalência de vermifugação $(52,6 \%)$ ou apenas um animal $(47,4 \%)$. A grande maioria dos entrevistados que não souberam informar sobre a vermifugação de seus animais (8\%), possuem mais de um animal de companhia (63\%), quando comparado com os entrevistados que declararam ter vermifugado seus animais ou não (Tabela 11). 
Research, Society and Development, v. 10, n. 6, e4210615450, 2021

(CC BY 4.0) | ISSN 2525-3409 | DOI: http://dx.doi.org/10.33448/rsd-v10i6.15450

Tabela 9: Dados sobre vacinação e castração de cães e gatos.

\begin{tabular}{|c|c|c|c|}
\hline Cães e gatos & Entrevistados & $\%$ & Entrevistados que possuem cães e gatos \% \\
\hline Animal vacinado & 252 & 75,0 & \\
\hline Animal castrado & 72 & 28,6 & 21,4 \\
\hline Maioria castrado & 23 & 9,1 & 6,8 \\
\hline Maioria não castrado & 14 & 5,6 & 4,2 \\
\hline Não castrado & 143 & 56,7 & 42,6 \\
\hline Animal não vacinado & 60 & 17,9 & \\
\hline Animal castrado & 13 & 21,7 & 3,9 \\
\hline Maioria castrado & 5 & 8,3 & 1,5 \\
\hline Maioria não castrado & 5 & 8,3 & 1,5 \\
\hline Não castrado & 37 & 61,7 & 11,0 \\
\hline Não soube responder & 24 & 7,1 & \\
\hline Animal castrado & 6 & 25,0 & 1,8 \\
\hline Maioria castrado & 1 & 4,2 & 0,3 \\
\hline Maioria não castrado & 1 & 4,2 & 0,3 \\
\hline Não castrado & 16 & 66,7 & 4,8 \\
\hline Total & 336 & 100 & 100 \\
\hline
\end{tabular}

Fonte: Autores.

Tabela 10: Dados sobre renda familiar e frequência de consultas de seus cães e gatos no veterinário.

\begin{tabular}{lcc}
\hline $\begin{array}{l}\text { Frequência que leva seu animal ao } \\
\text { veterinário }\end{array}$ & $\begin{array}{c}\text { Entrevistados que possuem cães e } \\
\text { gatos }\end{array}$ & $\%$ \\
\hline Até 1 salário mín. & 7 & 2,1 \\
\hline Não leva ao veterinário & 2 & 28,6 \\
Apenas quando necessário & 4 & 57,1 \\
Anualmente & 1 & 14,3 \\
\hline De 1 a 2 salários mín. & 67 & 19,9 \\
\hline Quinzenalmente & 1 & 1,5 \\
Mensalmente & 4 & 6,0 \\
A cada três meses & 5 & 7,5 \\
A cada seis meses & 2 & 3,0 \\
Anualmente & 1 & 1,5 \\
Apenas quando necessário & 50 & 74,6 \\
Não leva ao veterinário & 4 & 6,0 \\
\hline De 2 a 5 salários mín. & 149 & 44,3 \\
\hline Semanalmente & 2 & 1,3 \\
Quinzenalmente & 2 & 1,3 \\
Mensalmente & 6 & 4,0 \\
A cada três meses & 7 & 4,7 \\
A cada seis meses & 6 & $\begin{array}{l}\text { (n) } \\
\text { Anualmente }\end{array}$ \\
\hline
\end{tabular}


Research, Society and Development, v. 10, n. 6, e4210615450, 2021

(CC BY 4.0) | ISSN 2525-3409 | DOI: http://dx.doi.org/10.33448/rsd-v10i6.15450

\begin{tabular}{lcc} 
Apenas quando necessário & 104 & 69,8 \\
Não leva ao veterinário & 8 & 5,4 \\
\hline De 5 a l0 salários mín. & 78 & 23,2 \\
\hline Mensalmente & 2 & 2,6 \\
A cada três meses & 4 & 5,1 \\
A cada seis meses & 3 & 3,8 \\
Anualmente & 5 & 6,4 \\
Apenas quando necessário & 59 & 75,6 \\
Não leva ao veterinário & 5 & 6,4 \\
\hline Mais que 10 salários mín. & 34 & 10,1 \\
\hline Semanalmente & 3 & 8,8 \\
Mensalmente & 3 & 8,8 \\
A cada três meses & 2 & 5,9 \\
A cada seis meses & 2 & 5,9 \\
Anualmente & 1 & 2,9 \\
Apenas quando necessário & 22 & 64,7 \\
Não leva ao veterinário & 1 & 2,9 \\
\hline Nenhuma renda & 1 & 0,3 \\
\hline Não leva ao veterinário & 336 & 100,0 \\
\hline Total & & \\
\hline
\end{tabular}

Fonte: Autores.

Tabela 11: Dados sobre vermifugação de cães e gatos e quantidade dos mesmos por residência.

\begin{tabular}{lccc}
\hline Cães e gatos & Entrevistados & $\%$ & Entrevistados que possuem cães e gatos \% \\
\hline Animal vermifugado & 247 & 73,5 & \\
\hline Apenas 1 animal & 117 & 47,4 & 34,8 \\
$>1$ animal & 130 & 52,6 & 38,7 \\
\hline Animal não vermifugado & 62 & 18,5 & 10,7 \\
\hline Apenas 1 animal & 36 & 58,1 & 7,7 \\
$>1$ animal & 26 & 41,9 & 3,0 \\
\hline Não soube responder & 27 & 8,0 & 5,1 \\
\hline Apenas 1 animal & 10 & 37,0 & \\
$>1$ animal & 17 & 63,0 & $\mathbf{1 0 0}$ \\
\hline Total & $\mathbf{3 3 6}$ & & \\
\hline
\end{tabular}

Fonte: Autores.

\section{Discussão}

Estudos que avaliam o perfil socioeconômico dos tutores correlacionando ao perfil de guarda responsável de animais de companhia e sobre zoonoses, têm sido realizados em várias localidades do Brasil (Andrade et al., 2015; Predrassani e Karvat, 2017; Paula et al., 2018; Lacerda et al., 2020), assim como também em alguns municípios no estado do Paraná 
(Catapan et al., 2015). Até o presente momento, este é o primeiro estudo realizado no município de Maringá/Paraná, o que destaca sua importância.

Observou-se que entre os entrevistados, houve maior prevalência do sexo feminino. Em relação ao tipo de residência, a grande maioria dos entrevistados reside em casas, possivelmente este elevado número se deve ao fato de casas serem mais acessíveis para realização da pesquisa, quando comparadas com apartamentos. Ambos os dados foram semelhantes aos estudos de Catapan et al., (2015), Pedrassani e Karvat (2017) e Lacerda et al., (2020) que verificaram maior número de mulheres entrevistadas e casas como residência, com exceção do trabalho de Andrade et al. (2015), ao qual a grande maioria de entrevistados foi do sexo masculino.

$\mathrm{Na}$ análise de idade dos entrevistados, foi possível observar que a grande maioria possui entre 10 e 30 anos, acreditando-se ser devido à idade com maior predominância na cidade de Maringá - PR (IPARDES, 2021). A prevalência de idade corrobora com os estudos de Andrade et al. (2015) e Oliveira (2018). Catapan et al., (2015) obteve resultados de faixa etária com maior prevalência de 10 a 40 anos, entretanto, Pedrassani e Karvat (2017), identificaram maior prevalência em idade média de 45 anos.

A grande maioria dos entrevistados possui graduação completa, sendo possivelmente, pela grande quantidade de universidades da cidade de Maringá, conforme já relatado por IPARDES (2021). Ao comparar com o trabalho de Catapan et al., (2015), podemos identificar semelhanças nos resultados quanto à escolaridade, ao qual a grande maioria possui ensino superior completo, mas Pedrassani e Karvat (2017) identificaram maior prevalência em entrevistados com ensino médio completo e apenas um baixo percentual com ensino superior completo, da mesma forma que Gomes (2015), que identificou apenas um pequeno percentual com ensino superior completo. Lacerda et al. (2020) observaram 46\% dos entrevistados apresentando o ensino médio completo ou incompleto e apenas $20 \%$ com ensino superior.

A grande maioria dos entrevistados desta pesquisa possui graduação completa, mas, independentemente de sua formação acadêmica, a renda dominante foi de 2 a 5 salários mínimos. Acredita-se atribuir a predominância de entrevista com renda familiar entre 2 a 5 salários mínimos, pelo fato de que a população de Maringá possui salário médio de 2,7 salários mínimos, de acordo com o IBGE (2017). Porém, foi possível constatar que, conforme aumenta o nível de escolaridade, a renda familiar é maior. Pedrassani e Karvat (2017) encontraram dados semelhantes, sendo predominante 1,3 a 3 salários mínimos, e da mesma forma que Gomes (2015), em que a renda predominante foi de até 2 salários mínimos.

Uma pequena minoria dos entrevistados não possui animais de estimação, principalmente pelos motivos de não possuírem espaço ou por falta de tempo para se dedicarem aos animais. Importante ressaltar esses dados, pois ele reflete a conscientização da população, tendo em vista que os animais necessitam expressar seus comportamentos naturais, com espaço e instalações adequadas para seu bem-estar, juntamente com tratamento adequado, para que não haja sofrimento psicológico (OIE, 2017). Na pesquisa de Ortunho, Carvalho, Baldassi e Teixeira (2013), o percentual de quem não possui animais de estimação foi de $5 \%$, ou seja, menor do que a atual pesquisa.

Outra hipótese para uma mínima quantidade dos entrevistados não possuírem animais de estimação são os custos gerados. Uma pesquisa de mercado pet realizado na cidade de Natal em 2018, observou que os tutores estão cada vez mais preocupados com o bem-estar e saúde de seus animais, assim, não havendo imposição ao custo de vida gerado de seus animais, acreditando-se ser por isso um percentual tão baixo (Oliveira, 2018)

O Brasil fica apenas atrás dos Estados Unidos da América quando se trata de maior população canina e felina do mundo (Nasser \& Fluke, 1991; Domingues, 2012; Loss et al., 2012). A grande maioria dos entrevistados possuem animais de estimação, sendo que a maioria destes possuem apenas cão como animal de estimação, seguido por ambos (cães e gatos) e por fim, apenas gatos, mesmos resultados encontrados por Gomes (2015). 
Domingues (2012), descreveu que a grande maioria dos entrevistados tem preferência por criar unicamente cães como animais de companhia, da mesma forma que Gomes (2015), Pedrassani e Karvat (2017), Catapan et al., (2015) e Oliveira (2018). Essa preferência por cães destacada em diversos trabalhos pode ser devido ao comportamento mais afetivo e de contato corporal dos cães, além do sentimento de proteção a seus tutores (Fuck et al., 2006), diferentemente dos gatos, aos quais são mais independentes, não se incomodando também em ficar sozinhos (Pereira \& Pereira, 2013).

No estudo de Gomes (2015), quase o total dos entrevistados (98,19\%) possuem até 5 cães ou 5 gatos em sua residência, dados estes semelhantes a este trabalho. Observou-se que, independentemente do sexo, a grande maioria dos entrevistados possuem um ou dois cães / gatos. Catapan et al., (2015), descreve que a grande maioria dos entrevistados possui apenas um cão ou um gato como animais de companhia, semelhante aos resultados encontrados no atual trabalho, mas o mesmo não cita prevalência de espécie relacionado ao sexo do entrevistado. Paula et al. (2018) verificaram número médio de cães $(1,29)$ e gatos $(0,27)$ por residência inferiores com relação aos resultados obtidos em nossa pesquisa $(1,81$ e 1,55 , respectivamente, por residência), isso evidencia que o perfil populacional deve ser estudado individualmente para cada localidade

A grande maioria dos entrevistados informaram não castrar seus animais, e boa parte destes animais possuem acesso livre à rua. Diversos trabalhos identificaram que a maioria dos entrevistados não castram seus animais, obtendo resultados semelhantes à atual pesquisa (Lima et al., 2010; Pedrassani \& Karvat, 2017; Ortunho et al., 2013; Andrade et al., 2015; Catapan et al., 2015; Gomes, 2015). De acordo com Joffily, Souza, Gonçalves, Pinto, Barcellos e Alonso (2013), a castração, ou esterilização dos animais, seria uma política mais eficiente e uma forma mais humanitária do controle de zoonoses. Além disso, deve ser levado em consideração pelos tutores na decisão de castrar seus animais a reprodução descontrolada e a redução da chance de os animais serem agressivos com outras pessoas, cuja agressividade pode ser causada pela mudança comportamental, visto que animais esterilizados mordem três vezes menos do que os não esterilizados (Hodge, 1976; Sacks, Lockwood, Horneich, \& Sattin, 1999; Souza, 2017; Bortoloti \& D’agostino, 2007).

Um estudo de Marston, Bennett, \& Coleman (2004) identificou três abrigos de animais na Austrália, aos quais a grande maioria dos animais abandonados não eram castrados e com histórico de agressão a seres humanos. Além da agressividade do animal, algumas doenças podem ser desenvolvidas ou transmitidas aos animais não castrados, como doenças venéreas, distocias, infecções uterinas e testiculares, tumores uterinos, ovarianos, prostáticos e mamários, sendo reduzido risco ou eliminado com a castração do animal (Soares \& Silva, 1998). Hopkins et al. (1976) e Maarschalkerweerd (1997) realizaram estudos semelhantes, onde cães eram castrados a fim de obter mudança comportamental de redução na demarcação de território e agressividade contra seres humanos e, ambas pesquisas obtiveram resultados satisfatórios, havendo redução destes comportamentos.

A prefeitura de Maringá, no ano de 2017, criou a Diretoria de Bem-Estar animal, e vem realizando castrações gratuitas e atendimento aos animais abandonados, através de aplicativo de celular e ouvidoria telefônica e digital (Diretoria de comunicação, 2019). Apesar da iniciativa introduzir a castração e atendimento veterinário no cenário municipal, os autores acreditam que o resultado desta pesquisa ainda não foi impactado por recentes ações da prefeitura, uma vez que há um período de adaptação da população e assimilação para a política pública implementada.

A pesquisa de Catapan et al. (2015) relata que um pequeno percentual de tutores mantém seus animais com acesso livre às vias públicas. O atual trabalho e de Domingues (2012) apresentaram dados semelhantes e com percentual maior quando comparado com a pesquisa de Catapan et al. (2015). O elevado percentual de animais com acesso livre às ruas deve-se à comodidade do tutor, ao qual não precisa acompanhar seus animais durante seus passeios e necessidades, entretanto, ARCA Brasil (2021) relata que uma das medidas de posse responsável é que seu animal seja mantido dentro de casa e, seu acesso à rua deve ser único e exclusivamente acompanhado do responsável e equipado com guia de passeio. 
Muitos tutores acreditam que deixar seus animais passearem, causará apenas benefícios, como manter bom escore corporal, menor agressividade e menos agitação, mas o animal que realiza seus passeios pode apresentar tanto sobrepeso como inquietação, ou seja, passeio não possui contribuição satisfatória para o animal (Ferreira \& Sampaio, 2010), no entanto, o atual trabalho não identificou dados estatísticos notórios de agressividade dos animais comparáveis a estes autores, nem no aspecto comportamental relacionado ao tipo de residência (casa ou apartamento).

No atual trabalho, foi possível identificar que, independentemente da renda familiar ou grau de escolaridade, a grande maioria oferece exclusivamente ração para seus animais, seguido por ração juntamente com comida caseira e, em apenas alguns casos, os alimentam apenas de comida caseira. Os trabalhos de Lima et al., (2010) e Oliveira e Souza (2019) obtiveram a mesma sequência de resultados que a atual pesquisa, entretanto, percentual mais baixo de animais alimentados exclusivamente com ração e percentual mais alto de animais alimentados com ração juntamente com comida caseira. Importante ressaltar que diversos tutores vêm optando apenas por ração como fonte de alimento para seus animais, por ser um alimento completo nutricionalmente (Felix et al., 2009).

Percebe-se que a grande maioria dos tutores reconhece a importância da vacinação de seus animais de companhia, atitude está presente nos cuidados básicos para bem-estar animal (Reichmann et al., 2000). Entretanto, tanto na atual pesquisa, assim como, no trabalho de Catapan et al., (2015), a grande maioria não castra seus animais, até mesmo os que possuem vacinas em dia. Os tutores estão cada vez mais atentos às necessidades de saúde de seus animais de companhia, investindo na saúde de seu animal, sendo com vacinação ou vermifugação (Oliveira, 2018). Lacerda et al. (2020) destacam a importância de campanhas municipais de vacinação, em seu estudo $93,43 \%$ dos animais receberam vacinação antirrábica, porém, para os demais protocolos vacinais, verificou-se negligência por parte da população, devido falta de conhecimento e custo econômico, segundo os autores. Estudos pormenorizados são necessários para identificar qual é a vacina que está sendo aplicada e sobre o conhecimento a respeito do protocolo vacinal. Paula et al. (2018) observaram que 70\% dos entrevistados declararam que cães e gatos receberam vacina antirrábica e $67,1 \%$ contra outras viroses.

De acordo com a pesquisa de Oliveira (2018), a maioria dos entrevistados mantém a vermifugação de seus animais em dia, resultado também obtido no trabalho de Gomes (2015), semelhante à atual pesquisa em que a maioria dos animais foram vermifugados no último ano. Estudo do perfil demográfico realizado no mesmo ano deste estudo, no bairro Efapi, município de Chapeco/SC, 92,9\% dos entrevistados declararam tratar seus animais com antiparasitários (Paula et al.,2018) Independentemente da renda dos entrevistados, foi verificado que os tutores levam seus animais ao veterinário apenas quando necessário, havendo uma minoria que não leva seu animal ao veterinário. Estes resultados foram semelhantes ao trabalho de Pedrassani e Karvat (2017), que complementaram observando que, quanto maior o conhecimento de bem-estar animal, maior a frequência com que os tutores levam seus animais ao médico veterinário. No trabalho realizado por Lacerda et al. (2020) observou-se que $75 \%$ dos entrevistados nunca levaram seu animal de estimação ao veterinário, sendo que os maiores percentuais quanto à escolaridade foram de $46 \%$ e $31 \%$ para ensino médio e fundamental. No trabalho realizado por Oliveira e Sousa (2019) observou-se que visitas regulares ao médico veterinário não teve influência de escolaridade, renda ou faixa etária, entretanto, os percentuais obtidos foram reduzidos quanto comparado aos resultados obtidos neste estudo. Destacam Paula et al. (2018) que a escolaridade é um importante fator na saúde dos tutores e na qualidade da tutoria e bem-estar dos animais de companhia.

\section{Conclusão}

Em conclusão, identificou-se que a amostra estudada foi constituída principalmente por mulheres, adultos-jovens, residentes em casas, com elevada instrução escolar e com renda familiar de dois a cinco salários mínimos. Grande parte dos entrevistados possuem animais de estimação, sendo o cão o animal comumente encontrado nas residências maringaenses. 
Observou-se o conhecimento da guarda responsável e sua importância em seus diferentes aspectos, desde o que tange os entrevistados que possuem animais, onde constatou-se que a maioria dos animais foram adquiridos por adoção, nas residências ficam soltos, possuem "acomodações" próprias (casas e camas), recebem ração como principal fonte de alimentação e em sua maioria são vacinados e vermifugados, até os entrevistados que não possuem animal de companhia, que conscientemente não os possuem, por não ter espaço ou tempo para cuidar. Assim, as práticas de bem-estar animal são parte integrante dos hábitos da população.

Contudo, alguns aspectos carecem de atenção, pois grande parte dos entrevistados não castraram seus animais, permitem que eles tenham acesso a vias públicas e levam seus pets ao veterinário apenas quando necessário, fator este último influenciado pela renda familiar.

Programas de conscientização quanto ao controle populacional e acesso as ruas de animais de companhia e programas de castração, devem ser implementadas por órgãos públicos e instituições de ensino superior com objetivo de aproximar a população dos importantes aspectos da guarda responsável. Adicionalmente, novos estudos devem ser realizados para desvendar as inúmeras interfaces associadas a guarda responsável e bem-estar animal, como por exemplo a saúde psicológica de animais de companhia e maus tratos.

\section{Referências}

Andrade, F. T. M., Araújo, C. L., Paulo, O. L. O. H., Rocha, J. R., Dias, F. G. G., Pereira, L. F., Jorge, A. T., \& Honsho, C. S. (2015) Posse responsável: uma questão multidisciplinar. Acta Veterinaria Brasilica, 9(1), 91 - 97.

ARCA Brasil. (2021). 10 Mandamentos da guarda responsável. Recuperado em 20 de abril, de https://arcabrasil.org.br/index.php/10-mandamentos-daguarda-responsavel/

Bortoloti, R., \& D`agostino, R. G. (2007) Ações pelo controle reprodutivo e posse responsável de animais domésticos interpretadas à luz do conceito de metacontingência. Revista Brasileira de Análise do Comportamento, 3(1), 17 - 28.

Broom, D. M., \& Fraser, A. F. (2010). Comportamento e bem-estar de animais domésticos (4a ed.). Manole

Canatto, B. D., Silva, E. A., Bernardi, F., Mendes, M. C. N. C., Paranhos, N. T., \& Dias, R. A. (2012) Caracterização demográfica das populações de cães e gatos supervisionados do município de São Paulo. Arquivo Brasileiro Medicina Veterinária Zootecnia, 64(6), 1515 - 1523.

Catapan, D. C., Villanova-Junior, J. A., Weber, S. H., \& Rocha, R. M. V. M. (2015) Percepção e atitudes de amostra populacional sobre guarda responsável, zoonoses e cães em vias públicas. Revista Brasileira de Ciência Veterinária, 22(2), 92 - 97.

Ciampo, L. A. D., Riccoa, R. G., Almeida, C. A. N., Bonilhac, L. R. C. M., \& Santos, T. C. C. (2000). Acidentes de mordeduras de cães na infância. Revista de Saúde Pública, 34(4), $411-412$.

Cohen, S. P. (2002). Can Pets Function as Family Members? Western Journal of Nursing Research, 24(6), 621- 638. 10.1177/019394502320555386.

Dilly, B. L. G., Costa-Júnior, N. B., Freitas, R. B., \& Franceschini, E. M. (2005) Tratamento dado ao problema de abandono de cães na UNICAMP. Revista Ciências do Ambiente. 1, 1 - 7.

Diretoria de comunicação. (2019). Aplicativo vai facilitar pedidos de castração e serviços. Portal da Prefeitura de Maringá. http://www2.maringa.pr.gov.br/site/index.php?sessao=db5f297ff355db\&id=34844.

Domingues, L.R. (2012). Posse responsável de cães e gatos na área urbana do município de Pelotas, RS, Brasil. Dissertação de mestrado, Universidade Federal de Pelotas, Pelotas. RS, Brasil

Felix, A. P., Sá-Fortes, C. M. L., Silva, A. C. M., Nascimento, S. T., Carciofi, A. C., Laurentiz, A. C., \& Bergamaschine, A. F. (2009). Digestibilidade de uma dieta caseira e dois alimentos comerciais, econômico e super-prêmio, para cães. Archives of Veterinary Science, 14(1), 25 - 30. 10.5380/avs.v14i1.13228.

Ferreira, S. A., \& Sampaio, I. B. M. (2010) Relação Homem-Animal e Bem-Estar do Cão Domiciliado. Archives of Veterinary Science, 15 (1), 22 - 35.

Figueiredo, A. C. C. (2001). Eutanásia animal em centros de controle de zoonoses. Revista do Conselho Federal de Medicina Veterinária, 7(23), 12 - 17.

Fortes, F. S., Wouk, A. F. P. F., Biondo, A. W., \& Barros, C. C. (2007). Acidentes por mordeduras de cães e gatos no município de Pinhais, Brasil de 2002 a 2005. Archives of Veterinary Science, 12(2), 16 - 24. http://dx.doi.org/10.5380/avs.v12i2.9904

Fox, J. (2005). The R Commander: A Basic-Statistics Graphical User Interface to R. Journal of Statistical Software, 14(9), 1-42.

Fuck, E. J., Fuck, E. T., Delarissa, F. \& Curti, C. E. (2006). Relação homem x Animal: aspectos psicológicos e comportamentais. Revista Nosso Clínico, 8(49), $46-58$. 
Gomes, V. C. P. S. (2015). Relação entre padrão socioeconômico e variáveis ligadas ao bem-estar e guarda responsável de cães e gatos em Areia - PB. Trabalho de Conclusão de Curso, Universidade Federal da Paraíba, Areia, PB, Brasil.

Grandjean, D., \& Vaissaire, J. P. (2001). Enciclopédia do cão Royal Canin. Aniwa Publishing.

Heffner, H. E. (1999). The symbiotic nature of animal research. Perspectives in biology and medicine, 43(1), 127 - 139.

Hodge, G. H. (1976). The reign of dogs and cats' or contemporary concepts of animal control. Management Information Service Report, 8(10), 1 - 20.

Hopkins, S. G., Schubert, T. A., \& Hart, B. L. (1976). Castration of adult male dogs: effects on roaming, aggression, urine marking, and mounting. Journal of American Veterinary Medical Association, 168, 1108 - 1110.

IBGE. População. https://cidades.ibge.gov.br/brasil/pr/maringa/panorama.

IPARDES, Instituto Paranaense de Desenvolvimento Econômico e Social. (2021). Caderno Estatístico Município de Maringá. http://www.ipardes.gov.br/cadernos/MontaCadPdf1.php?Municipio=87000\&btOk=ok

Joffily, D., Souza, L. M., Gonçalves, S. M., Pinto, J. V., Barcellos, M. C. B., \& Alonso, L. S. (2013). Medidas para o controle de animais errantes desenvolvidas pelo grupo Pet Medicina Veterinária da Universidade Federal Rural do Rio de Janeiro. Em extensão, 12(1), 197-221.

Lacerda, L. M., Gomes, J. W. M., Rosário, C. J. R. M., Silva, C. M., Bezerra, N. P. C., \& Melo, F. A. (2020). Avaliação do nível de conhecimento da população de São José de Ribamar-MA sobre zoonoses e posse responsável de animais domésticos. ARS Veterinaria, 36(4), 271-277. http://dx.doi.org/10.15361/2175-0106.2020v36n4p271-277

Lei $n^{\circ}$ 10.467, de 26 de outubro de 2017 (2017). Estabelece no âmbito do Município de Maringá sanções e penalidades administrativas para aqueles que praticarem maus-tratos aos animais e dá outras providências. Maringá. 2017. http://www2.maringa.pr.gov.br/sistema/arquivos/b9478620e050.pdf

Lei $n^{\circ}$ 10.406, de 10 de janeiro de 2002. (2002). Institui o Código Civil. Brasília. (2002). https://www.planalto.gov.br/ccivil_03/leis/2002/110406.htm

Lei $n^{\circ}$ 14.064, de 29 de setembro de 2020. (2020). Altera a Lei $\mathrm{n}^{\circ}$ 9.605, de 12 de fevereiro de 1998, para aumentar as penas cominadas ao crime de maustratos aos animais quando se tratar de cão ou gato. Brasília. (2020). http://www.planalto.gov.br/ccivil_03/_ato2019-2022/2020/lei/L14064.htm.

Lima, F. F., Neto, L. C., Koivisto, M. B. K., \& Perri, S. H. V. (2010). Avaliação dos conceitos sobre posse responsável exercida pela terceira idade em instituições não governamentais de Araçatuba-SP. Revista Ciência em Extensão, 6(2), 132 - 142.

Loss, L. D., Mussi, J. M. S., Mello, I, N. K., Leão, M. S., \& Franque, M. P. (2012). Posse responsável e conduta de proprietários de cães no município de Alegre-ES. Acta Veterinária Brasílica, 6(2), 105 - 111. https://doi.org/10.21708/avb.2012.6.2.2625.

Luescher, A. U. (2017). Canine behavior and development. In J. Shaw \& D. Martin (Ed.). Canine and Feline Behavior for Veterinary Technicians and Nurses. (Cap. 2, pp. 30-50). New Jersey: Wiley-Blackwell

Maarschalkerweerd, R. J, Endenburg, N., Kirpensteijn, J., \& Knol, B. W. (1997). Influence of orchiectomy on canine behaviour. Veterinary Record, 140,617 619 .

Marconi, M. A., \& Lakatos, E. M. (2019). Técnicas de Pesquisa. In M. A. Marconi \& E. M. Lakatos. Fundamentos da Metodologia Científica (8a ed. Cap. 9 , pp. 189-234). São Paulo: Atlas

Marston, L. C., Bennett, P. C., \& Coleman, G. J. (2004). What happens to shelter dogs? An analysis of data for 1 year from three Australian shelters. Journal of Applied Animal Welfare Science, 7(1), 27 - 47. https://doi.org/10.1207/s15327604jaws0701_2.

Mori, K. (2020). Cachorros ajudam seus donos a ter uma vida melhor. https://www1.folha.uol.com.br/folha/cotidiano/ult95u12176.shtml.

Nasser, R., \& Fluke, J. (1991). Pet population dynamics and community planning for animal welfare and animal control. Journal of the American Veterinary Medical Association. 198, 1160 - 1164.

OIE. Organização mundial de saúde animal. (2017). Estrategia Mundial de bienestar animal de la OIE. https://www.gov.br/agricultura/ptbr/assuntos/sustentabilidade/bem-estar-animal/arquivos/ES_OIE_AW_Strategy.pdf

Oliveira, A. B. A. (2018). O mercado pet na cidade de Natal: ofertas e expectativas sob a ótica dos consumidores. Trabalho de Conclusão de Curso, Universidade Federal do Rio Grande do Norte, Natal, RN, Brasil

Oliveira, R. P. \& Sousa, M. B. (2019). Conscientização e posse responsável de animais domésticos em Belém do Pará. Trabalho de conclusão de curso, Universidade Federal Rural da Amazônia, Belém, PA, Brasil.

Ortunho, V. V., Carvalho, G. S. P., Baldassi, G. C., \& Teixeira, N. M. (2013) Pesquisa epidemiológica sobre conhecimento de posse responsável em Ilha Solteira-SP. PUBVET, 7(7), 549-618.

Paula, J. M., Santos, C. G., Canalli, V., Fritzen, D. M. M., Busato, M.A., \& Lutinski, J. A. (2018). Population profile of dogs and cats and animal welfare in Chapecó, SC. Revista Brasileira de Higiene e Sanidade Animal, 12(4), 437 - 449.

Pedrassani, D., \& Karvat, D. C. (2017). Conhecimento sobre bem-estar e guarda responsável de cães e gatos domiciliados e semi-domiciliados. Revista Ciência em Extensão, 13(4), 55 - 63.

Pereira, G. G., \& Pereira, J. T. (2013). Comportamento social dos gatos. In C. B. Faraco \& G. M. Soares. Fundamentos do comportamento canino e felino (Cap. 12, pp.145-160). São Paulo: Editora Med Vet. 
Research, Society and Development, v. 10, n. 6, e4210615450, 2021

(CC BY 4.0) | ISSN 2525-3409 | DOI: http://dx.doi.org/10.33448/rsd-v10i6.15450

Reichmann, M. L. A. B., Figueiredo, A. C. C., Pinto, H. B. F., \& Nunes, V. F. P. (2000). Controle de populaçães animais de estimação [Manual]. São Paulo: Instituto Pasteur.

Sacks, J. J., Lockwood, R., Horneich, J., \& Sattin, R. W. (1999). Fatal dog attacks. Pediatrics, 97, 891-895.

Santana, L. R., \& Oliveira, T. P. (2006). Guarda responsável e dignidade dos animais. Revista Brasileira de Direito Animal, 1(1), 67-102. DOI: 10.9771/rbda.v1i1.32362.

Santos, S, V., \& Castro, J.M. (2006). Ocorrência de agentes parasitários com potencial zoonótico de transmissão em fezes de cães domiciliados do município de Guarulhos, SP. Arquivos do Instituto Biológico, 73, 255-257.

Selby, L. A., Rhoades, J. D., Hewett. J. E., \& Irvin, J.A. (1979). A survey of attitudes toward responsible pet ownership. Public Health Reports, 94(4), 380 386.

Soares, J. A. G., \& Silva, P. A. R. (1998). Castração precoce em cães e gatos - revisão de literatura. Revista Clínica Veterinária, 3,34 - 40.

Souza, Y. T. O. (2017). Estimativa e controle populacional de cães e gatos atendidos pelo projeto vida digna itinerante (PVDI) em Soure/Ilha do Marajó. Trabalho de Conclusão de Curso, Universidade Federal Rural da Amazônia, Belém, PA, Brasil.

Young, M. S. (1985). The evolution of domestic pets and companion animals. Veterinary Clinics of North America: Small Animal Practice, $15(2), 297$ - 309. 10.1016/s0195-5616(85)50302-2

Webster, J. (2005). Introduction: Facts and Values. In J. Webster. Animal Welfare: Limping Towards Eden. (Cap. 1, pp. 1-23). New Jersey: Wiley-Blackwell 